\title{
BODY MASS INDEX;
}

VISCERAL FAT AND TOTAL BODY FAT DISTRIBUTION AND ITS RELATION TO

BODY MASS INDEX IN CLINICAL SETTING USING BIO-IMPEDANCE BODY

COMPOSITION MONITOR

1. Associate Professor Medicine FMH College of Medicine and Dentistry. Shadman Lahore.

2. Registrar,

Department of Medicine,

Fatima Memorial Hospital, Lahore.

3. Student $3^{\text {rd }}$ Year MBBS,

King Edward Medical College, Lahore.

Correspondence Address:

Dr. Rizwana Kitchlew

Associate Professor

FMH College of Medicine and

Dentistry.

Shadman, Lahore

riz102403@yahoo.com

Article received on:

09/12/2016

Accepted for publication:

$10 / 02 / 2017$

Received after proof reading:

$14 / 02 / 2017$

\section{Dr. Rizwana Kitchlew ${ }^{1}$, Dr. Aijaz Zeeshan Khan Chachar ${ }^{2}$, Sonia Latif ${ }^{3}$}

ABSTRACT... Background: Asians compared to Europeans are known to be at an increased risk of cardiovascular disease (CVD) risk factors. Obesity is a global cardio metabolic health and cancer risk. There is paucity of data regarding obesity in our local population. Aims \& Objectives: To evaluate Body Mass Index (BMI). Visceral fat content and body fat percentage using Bio-impedance body composition monitor. Thus to identify overweight and obese individuals with high visceral and body fat content the risk factors for cardio metabolic syndrome. Study Design: Cross sectional survey. Setting: Outpatient Department of Medicine, Fatima Memorial Hospital Lahore, Pakistan. Period: $15^{\text {th }}$ January to $20^{\text {th }}$ March 2016 . Material and Method: 250 patients above 18 years of age who reported in outdoor department were enrolled after informed consent in local language according to enrollment criteria. Approved by ethical review committee reference number FMS-2-2016-IRB-M-111. Their height and weight were measured and $\mathrm{BMI}$, visceral fat content and body fat percentage was calculated using bioimpedance body composition monitor. They were asked questions for pertinent co-morbidities. The statistical analysis was done using SPSS 22.0 version. Results: Out of 250 patients enrolled $144(58 \%)$ were females and $106(42 \%)$ were males. Mean age was $45 \pm 13$ years. Mean BMI was $29 \mathrm{~kg} / \mathrm{m}^{2}$. Above normal BMI was seen in $170(68 \%), 98(39 \%)$ were obese $(\mathrm{BMl}>30 \mathrm{~kg} /$ $\mathrm{m} 2$ ) and 80 (32\%) overweight (BMI 25-29.9). Above normal visceral fat content and body fat percentage was seen in $110(44 \%)$ and $191(76 \%)$ respectively. In the later group $100(67 \%)$ were females. Diabetes and hypertension were present in 63(64\%) obese patients among 30(73\%) with high visceral fat and in $90(60 \%)$ with high body fat percentage. Conclusion: A significant number of patients were overweight or obese with above normal visceral fat content and body fat percentage with female dominance in later group. They also had higher prevalence of diabetes and hypertension. Bio-impedance technique is useful simple inexpensive tool for initial assessment of visceral and body fat content in outdoor facility.

Key words: Pakistan, Obesity, Visceral fat, Body fat percentage, Bio-impedance monitor, Hypertension, Diabetes

Article Citation: Kitchlew R, Chachar AZK, Latif S. Body Mass Index; Visceral fat and total body fat distribution and its relation to body mass index in clinical setting using bioimpedance body composition monitor. Professional Med J 2017;24(2):326334. DOI: 10.17957/TPMJ/17.3815

\section{INTRODUCTION}

Global obesity numbers have shot up from 105 million people in 1975 to 641 million in 2014, according to the most comprehensive body mass index (BMI) trend analysis to date. ${ }^{1}$ Analyzing data from 186 countries, researchers report that if current trends continue, $18 \%$ of men and $21 \%$ of women worldwide will be obese by 2025 , and more than $6 \%$ of men and $9 \%$ of women will be severely obese $\left(\geq 35 \mathrm{~kg} / \mathrm{m}^{2}\right) .{ }^{1}$ Body fat tissue is distributed into two main compartments with different metabolic characteristics: subcutaneous adipose tissue (SAT) and visceral adipose tissue
(VAT). Both types are important but attention has been directed to visceral adiposity owing to its association with various metabolic medical disorders ${ }^{2}$, cardiovascular disease and several malignancies. .,4 $^{-1}$ Quantitative assessment of visceral obesity is important for evaluating the risk of these pathologies. The pattern of distribution of adipose tissue is dependent upon various factors including sex, age, race, ethnicity, genotype, diet, physical activity, hormone levels and medication. ${ }^{5}$ The percentage of adipose tissue is higher in women, elderly and overweight individuals. ${ }^{6,7}$ 
The International Agency for Research on Cancer now says there's sufficient evidence that absence of excess body fatness lowers the risk for eight additional cancers. Of note, positive doseresponse associations between BMI and risk were found for more than half the cancer sites, with relative risks generally ranging from 1.2 to 1.5 for overweight and from 1.5 to 1.8 for obesity. ${ }^{8,9}$

Visceral obesity is associated with metabolic disturbances, degree of pathology in several chronic diseases and poor prognosis so it is of great importance to identify methods that quantify adipose tissue accurately and can specifically depict VAT from total adipose tissue. This measurement is important in implementing curative and preventive health measures. Sophisticated equipment like computed tomography (CT) and magnetic resonance imaging (MRI) can provide direct measures of cross-sectional areas or volumetric measures of VAT. ${ }^{10}$ However these are time consuming, costly and difficult to use in epidemiological studies. The clinically most useful techniques are those that can be performed quickly by the bedside and provide instant results, without extensive technical training. Anthropometric measures as well as bioelectrical impedance analysis (BIA) are designed as such; however, give an indirect measure of VAT. The most commonly used measure for prediction of body fat percentage (BF \%) is Body Mass Index (BMI). ${ }^{11,12}$

Body composition calculation by the BIA method using body composition monitor BF508 is based on the fact that body fat has little electric conductivity whereas muscles, blood vessels and bones have high water content so easily conduct electricity. The monitor sends an extremely weak current of $50 \mathrm{kHz}$ and less than 500 micro A through the body to determine the body fat percentage. It uses height, weight, age and gender information to generate BMI, Body fat percentage and visceral fat level. Body fat percentage refers to the amount of body fat mass in regards to the total body weight expressed as a percentage. Visceral fat is fat surrounding internal organs. During course of day body water tends to shift to lower limbs so electrical impedance varies between upper and lower limbs. Since BF508 uses electrodes for both hands \&feet to take measurements it reduces the influence of fluctuations on results. Asians are known to be at an increased risk of cardiovascular disease (CVD) risk factors, ${ }^{13}$ attributed in part to differences in body build and fat distribution. ${ }^{14,15}$ Non-Caucasians tend to have more deposition of visceral fat that is central obesity. In light of this, the World Health Organization (WHO) in 2004 created Asian-specific BMI trigger points for public health action and lowered down traditional BMl cut-off points for overweight and obesity from $\geq 25 \mathrm{~kg} /$ $\mathrm{m}^{2}$ and $\geq 30 \mathrm{~kg} / \mathrm{m}^{2}$ to $\geq 23 \mathrm{~kg} / \mathrm{m}^{2}$ and $\geq 27.5 \mathrm{~kg} /$ $\mathrm{m}^{2}$ respectively to represent 'increased risk' and 'high-risk's categories, for future development of obesity associated complications. ${ }^{16,17}$

Pakistanadeveloping country of Asiahasits burden of obesity and associated diseases. Sufficient data based on obesity related parameters for our local population is not available. There is a need to collect data relevant to our region so that future strategies can be devised to tackle this high risk metabolic state.

\section{MATERIAL \& METHODS}

This study is a descriptive cross sectional survey carried out in medical out -patient department at Fatima Memorial hospital Lahore from $15^{\text {th }}$ January 2016 till 20 $0^{\text {th }}$ March 2016.Approval was taken from institute ethical committee. 250 patients with ages between 18 and 81 years were included after taking informed consent. Patients who were pregnant or undergoing dialysis, had implanted cardiac devices, fever, edema or were unable to stand, body builders and athletes were excluded.

It was ensured that measurements were made during daytime and not after vigorous exercise, bath or after alcohol or large water intake and at least 2 hours after meal intake to avoid variation in calculated body composition due to change in body water content because of these physical conditions. For evaluation of total body fat \& visceral fat OMRON (Karada Scan) body composition monitor model BF: 508 was used. 
All procedures were carried out according to manufacturer instructions. After the subjects had been guided to stand on the footplate of the device and gently grasped the two handgrips with arms held straight forward at 90 degrees, age and gender information were entered into the machine, a supervisor pushed the start button to perform assessment. BMI of all patients was calculated using height \& weight formula. Patients were divided on basis of BMl $(\mathrm{kg} / \mathrm{m} 2)$ in 4 groups, underweight $(<18.5)$, normal (18.5$24.9)$, overweight (25-29.9), obese $(>30)$ as per WHO guidelines for Asians.

The patients were also grouped according to WHO Asian-specific BMI trigger points for public health action into' increased risk' and 'high-risk' group, with cut-off points for overweight and obesity of $23-27.4 \mathrm{~kg} / \mathrm{m}^{2}$ and $\geq 27.5 \mathrm{~kg} / \mathrm{m}^{2}$ respectively. Body fat percentage results interpreted based on national institute of health $(\mathrm{NIH}) / \mathrm{WHO}$ guideline for BMI as low, normal, high, very high as per sex and age distribution. Visceral fat results were graded as normal, high and very high based on Omron Healthcare figures. Presence of associated metabolic disorders (DM, Hypertension, PCOS, Hypothyroidism, Cushing syndrome) in our study population was identified on basis of patients' interview. Age group and gender base prevalence of BMI, visceral fat \&body fat categories along with presence of metabolic disorders was also assessed.

\section{Data Analysis}

The statistical analysis was done using SPSS 22.0 version. Continuous variables like age, BMI values were expressed as mean $\pm S D$. Frequency and percentage were expressed for categorical variables like gender, diseases and categories of BMI, visceral and body fat. Chi-square test was applied and P-value $<0.05$ considered as significant.

\section{RESULTS}

Out of 250 patients enrolled 144 (57.6\%) were females and 106 (42.4\%) were males. Mean age was $45 \pm 13$ years. Mean BMl was $29 \mathrm{~kg} / \mathrm{m}^{2}$, $98(39 \%)$ were obese $80(32 \%)$ overweight and
$70(28 \%)$ normal. Among 178(71\%) with above normal BMI 110 (62\%) were females. Mean visceral fat score was 10 i.e high and 110 (44\%) participants had above normal values. However equal number of males and females had high visceral fat. Mean body fat percentage was 36 $\%$ i.e high, 191(76\%) had above normal body fat percentage out of these $119(82 \%)$ were females. Diabetes was present in $89(36 \%)$, Hypertension in $89(36 \%)$ and $10(4 \%)$ had hypothyroidism and 1 each had Cushing and Polycystic ovarian syndrome. Basic demographics shown in Table-l. The maximum number of patients 74 (27\%) belonged to age group 41-50 years and this group showed highest values in all three studied parameters shown in Table-II.

\begin{tabular}{|l|c|}
\hline \multicolumn{1}{|c|}{ Total number(N) } & $\mathbf{2 5 0}$ \\
\hline Gender & \\
Male & $106(42 \%)$ \\
Female & $144(57 \%)$ \\
\hline Mean Age( years) & $45 \pm 13$ \\
Minimum & 20.0 \\
Maximum & 78.0 \\
Mean Age Males & $47 \pm 14$ \\
Mean Age Females & $44 \pm 12$ \\
\hline Mean BMI (kg/m2) & 29 \\
\hline Mean Body Fat \% score level & 36 (high) \\
\hline Mean Visceral Fat score level & 10 (high) \\
\hline WHO Asian-specific BMl trigger points & \\
increased risk group (BMl> 23 kg/ m2) & $75(30 \%)$ \\
high-risk group(BMl >27.5 kg/m2) & $136(54 \%)$ \\
\hline Number of patients with & \\
Diabetes & 89 \\
Hypertension & 89 \\
Hypothyroidism & 10 \\
Cushing & 1 \\
Polycystic ovarian syndrome & 1 \\
\hline \multicolumn{1}{|c|}{ Table-I. Basic demographic, characteristics and } \\
\end{tabular}

In the 98 obese as per BMI, 93(95\%) had above normal fat percentage and $73(76.5 \%)$ had high visceral fat. Among obese, 63(64\%) had associated illnesses like diabetes and hypertension. Among 41 with very high visceral fat, 30(73\%) and among 150 with very high body fat percentage, $90(60 \%)$ had these diseases. In the categories of high BMl and high body fat percentage the number of females was more, 


\begin{tabular}{|c|c|c|c|c|c|c|c|c|c|c|c|c|c|c|}
\hline \multirow[b]{2}{*}{ Age Categories } & \multicolumn{5}{|c|}{ Body Mass Index } & \multicolumn{5}{|c|}{ Body Fat } & \multicolumn{4}{|c|}{ Visceral Fat } \\
\hline & 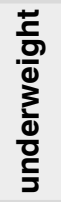 & $\begin{array}{l}\bar{\varpi} \\
\text { हू } \\
\text { ప }\end{array}$ & $\begin{array}{l}\text { 픙 } \\
\frac{0}{0} \\
\frac{3}{0} \\
0 \\
0\end{array}$ & 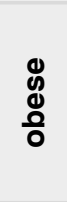 & 吾 & ב̇ & $\begin{array}{l}\overline{\text { बू }} \\
\text { है } \\
\text { zo }\end{array}$ & 战 & 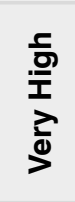 & $\begin{array}{l}\overline{\widetilde{\pi}} \\
\text { 음 }\end{array}$ & $\begin{array}{l}\overline{\widetilde{J}} \\
\text { है } \\
\text { z }\end{array}$ & 동 & 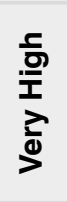 & $\begin{array}{l}\bar{\varpi} \\
\text { 。ँ }\end{array}$ \\
\hline $21-30$ & 2 & 19 & 14 & 10 & 45 & 1 & 13 & 10 & 20 & 44 & 34 & 6 & 4 & 44 \\
\hline $31-40$ & 0 & 14 & 12 & 19 & 45 & 1 & 9 & 8 & 29 & 47 & 35 & 11 & 5 & 51 \\
\hline $41-50$ & 0 & 15 & 28 & 35 & 78 & 0 & 12 & 13 & 52 & 77 & 37 & 22 & 16 & 75 \\
\hline $51-60$ & 0 & 11 & 11 & 28 & 50 & 0 & 11 & 6 & 34 & 51 & 19 & 19 & 12 & 50 \\
\hline $61-70$ & 0 & 8 & 12 & 4 & 24 & 2 & 7 & 4 & 10 & 23 & 13 & 8 & 1 & 22 \\
\hline $71-80$ & 0 & 3 & 3 & 2 & 8 & 1 & 2 & 2 & 3 & 8 & 2 & 3 & 3 & 8 \\
\hline Total & 2 & 70 & 80 & 98 & 250 & 5 & 54 & 41 & 150 & 250 & 140 & 69 & 41 & 250 \\
\hline
\end{tabular}

Table-II. Distribution of Body mass index(BMI), Body Fat and Visceral fat in various age groups categories

$76 \%$ and $82 \%$ respectively with respect to total females in study population as compared to males shown in Table-III. Percentage of males in each mentioned category was $64 \%$ and $68 \%$. Linear relation was seen between the BMI. The majority of studied population was in the higher category of all the three parameters studied as shown in table 3.This group also showed higher prevalence of associated diseases as well. Relationship between the three studied categories is significant and linear approximately (Table-III, Figure-1\&2).

\begin{tabular}{|l|c|c|c|c|c|c|c|}
\hline \multicolumn{1}{|c|}{ Categories } & Number & $\begin{array}{c}\text { Gender } \\
\text { (M:F) }\end{array}$ & Mean Age & $\begin{array}{c}\text { Associated } \\
\text { Illnesses }\end{array}$ & DM & Hypertension & Hypothyroidism \\
\hline $\begin{array}{l}\text { BMI } \\
\text { (category 3-4) }\end{array}$ & $\begin{array}{c}178 \\
\text { Overweight/ } \\
\text { Obese }\end{array}$ & $\begin{array}{c}(68: 110) \\
38 \%: 62 \%\end{array}$ & 46 & 109 & 70 & 78 & 7 \\
\hline $\begin{array}{l}\text { Body fat percentage } \\
\text { (high/very high) }\end{array}$ & $\begin{array}{c}191 \\
(41 / 150)\end{array}$ & $\begin{array}{c}(71: 119) \\
37 \%: 63 \%\end{array}$ & 45 & 103 & 67 & 76 & 8 \\
\hline $\begin{array}{l}\text { Visceral fat (high/ } \\
\text { very high) }\end{array}$ & $\begin{array}{c}110 \\
(69 / 41)\end{array}$ & $\begin{array}{c}(55: 55) \\
50 \%: 50 \%\end{array}$ & 49 & 71 & 46 & 51 & 7 \\
\hline
\end{tabular}

Table-III. Characteristics of Population in three categories i.e high BMI, high Body fat percentage and high Visceral fat.

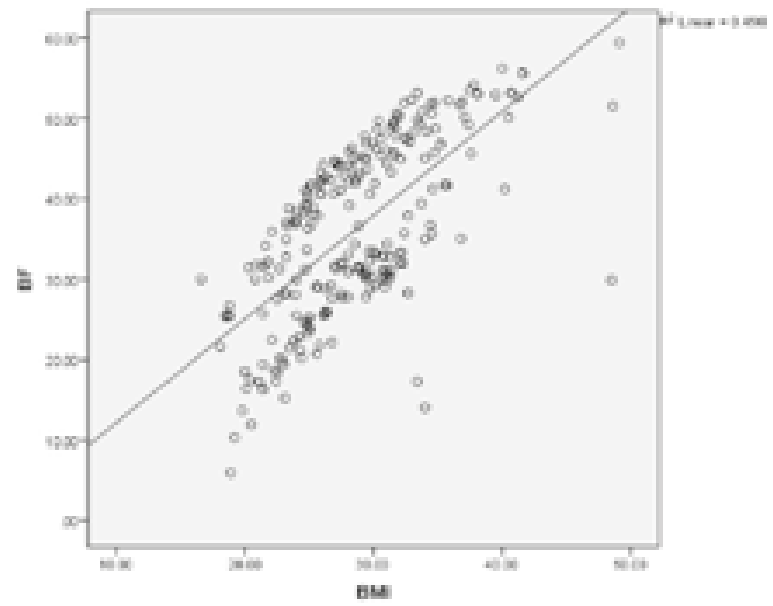

Figure-1. Scatter plot of relationship between Body Mass Index (BMI) and Body fat (BF) percentage of study population

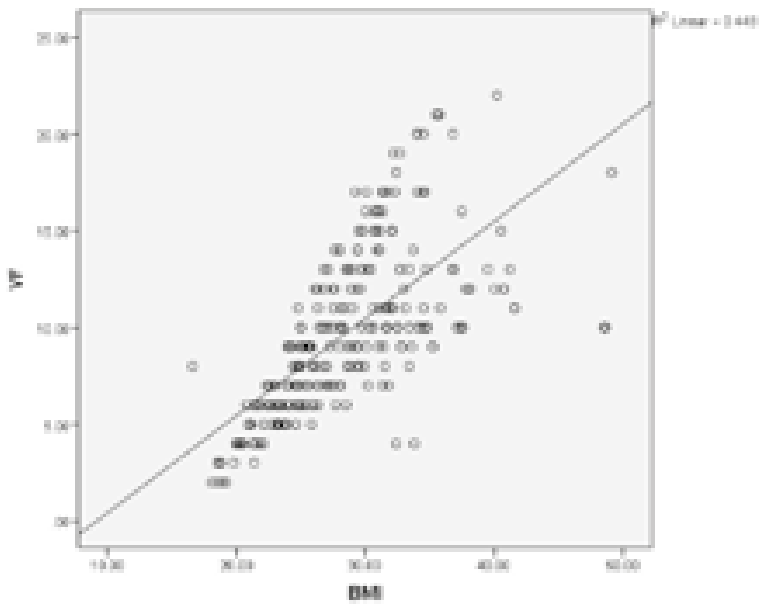

Figure-2. Scatter plot of relationship between Body Mass Index (BMI) and Visceral fat (VF) of study population 
According to WHO Asian-specific BMI trigger points for public health action, $75(30 \%)$ and $136(54 \%)$ represented 'increased risk' and 'highrisk' group respectively. In the high risk group $99(73 \%)$ had high or very high visceral fat and $131(96 \%)$ had high or very high body fat content.

\begin{tabular}{|l|c|c|}
\hline \multicolumn{1}{|c|}{ Variables } & $\begin{array}{c}\text { P-value (by using } \\
\text { chi square) }\end{array}$ & Remarks \\
\hline BMl and BF & 0.000 & Significant \\
\hline BF and VF & 0.000 & Significant \\
\hline BMl and VF & 0.000 & Significant \\
\hline BMl, BF and VF & 0.000 & Significant \\
\hline Table-IV. Statistical significance of various indicators \\
\hline
\end{tabular}

\begin{tabular}{|c|c|c|c|c|c|c|}
\hline \multirow{2}{*}{ Body mass index } & & & \multicolumn{3}{|c|}{ Visceral fat } & \multirow{2}{*}{ Total } \\
\hline & & & Normal (1-9) & High (10-14) & Very high (15-30) & \\
\hline \multirow{2}{*}{ Underweight $(<18.5)$} & Body fat & Normal (21-32.9) & 2 & & & 2 \\
\hline & \multicolumn{2}{|l|}{ Total } & 2 & & & 2 \\
\hline \multirow{5}{*}{$\begin{array}{l}\text { Normal } \\
(18.5-24.9)\end{array}$} & \multirow{4}{*}{ Body fat } & Low $(<21)$ & 4 & 0 & & 4 \\
\hline & & Normal (21-32.9) & 36 & 1 & & 37 \\
\hline & & High (33-38.9) & 20 & 1 & & 21 \\
\hline & & Very high (>39) & 8 & 0 & & 8 \\
\hline & \multicolumn{2}{|l|}{ Total } & 68 & 2 & & 70 \\
\hline \multirow{5}{*}{ Out overweight (25-29.9) } & \multirow{4}{*}{ Body fat } & Low $(<21)$ & 0 & 1 & 0 & 1 \\
\hline & & Normal (21-32.9) & 6 & 6 & 0 & 12 \\
\hline & & High (33-38.9) & 7 & 11 & 0 & 18 \\
\hline & & Very high (> 39) & 34 & 14 & 1 & 49 \\
\hline & \multicolumn{2}{|l|}{ Total } & 47 & 32 & 1 & 80 \\
\hline \multirow{4}{*}{$\begin{array}{l}\text { Obesity } \\
(\geq 30)\end{array}$} & \multirow{3}{*}{ Body fat } & Normal (21-32.9) & 3 & 0 & 0 & 3 \\
\hline & & High (33-38.9) & 0 & 0 & 2 & 2 \\
\hline & & Very high $(>39)$ & 20 & 35 & 38 & 93 \\
\hline & \multicolumn{2}{|l|}{ Total } & 23 & 35 & 40 & 98 \\
\hline \multirow{4}{*}{ Total } & \multirow{4}{*}{ Body fat } & Low $(<21)$ & 4 & 1 & 0 & 5 \\
\hline & & Normal (21-32.9) & 47 & 7 & 0 & 54 \\
\hline & & High (33-38.9) & 27 & 12 & 2 & 41 \\
\hline & & Very high (>39) & 62 & 49 & 39 & 150 \\
\hline
\end{tabular}

Table-V. Distribution of study population in various categories of three study parameters.

\section{DISCUSSION}

The prevalence of obesity has dramatically increased over the last several decades all over the world. According to WHO Global Health Observatory data in 2014 , around $39 \%$ of adults aged 18 years and above were overweight and $13 \%$ were obese. Average BMl of the world's population was $24 \mathrm{~kg} / \mathrm{m} 2$. Their data for Pakistan shows overweight $23 \%$ both sexes included, females $25.3 \%$ and males $20.8 \%$ and in obese category $5.4 \%, 7.3 \%, 3.7 \%$ respectively. In our study group overweight including both sex (80)32 $\%$, females (46)32\% \%, males (34)32 \%, figures for obesity (98) 39\%, (64) $44 \%$ and (34) $32 \%$ respectively. This shows higher number in each category. However our study sample size is small and limited to the patients reporting in the hospital. New data from a national survey of adults in the United States show, the age-adjusted prevalence of obesity in 2013-2014 was 35\% among men and $40 \%$ among women. ${ }^{18}$ Women's obesity and extreme obesity rates increased in the past decade, while rates did not increase significantly for men in either category. ${ }^{18}$ Our findings also shows greater prevalence of higher BMI and Body fat content among females.

Obesity is strongly associated with various clinical disorders and increase in morbidity and mortality. ${ }^{19}$ However it is a modifiable risk factor. Many studies have shown that abdominal visceral fat plays a key role in insulin resistance. ${ }^{20}$ Our study reveals higher prevalence of diabetes and hypertension in patients with higher BMI, body and visceral fat levels. A recent study in Pakistan estimated relation between anthropometric measures and BMI for obesity in hypertensive subjects. ${ }^{21}$ They categorized $56 \%$ hypertensive 
as overweight or obese and significantly higher prevalence of this category among females.

A large amount of visceral adipose tissue is a core component in subjects with metabolic syndrome. ${ }^{19,22,23}$ Thus accurate measurement of visceral fat area(VFA) is crucial in the assessment of cardio metabolic risk in an individual. ${ }^{24}$

$\mathrm{MRI}$ is considered the most accurate method for assessment of VFA, without exposure to radiation, however it is very expensive. ${ }^{25}$ The abdominal computed tomography (CT) another such tool but gives exposure to radiation plus is expensive. ${ }^{26}$ Both the modalities are neither readily available nor cost effective. Therefore using these during routine clinical care in a given disease population or in prospective analysis is less feasible.

On the other hand bioelectrical impedance analysis is noninvasive, simple, quick, and safe, cost-efficient, avoids exposure to radiation and is widely available. Thus can be used in routine clinical and research settings for classifying adipose tissue distribution for the initial diagnosis of abdominal obesity for individuals, and for general application in epidemiological studies..$^{27-29}$ We are a South Asian developing country with significant prevalance of cardio metabolic diseases. We need simple tools to assess the burden of obesity an important contributor to the public health issues and having negative economic impact.

There have been several experimental trials to estimate VFA in the abdomen using BIA and some of them showed good correlations between VFA estimated by BIA and that measured by precise imaging techniques such as CT. ${ }^{24,30,31}$

Moreover, studies have confirmed that VFA estimated by BIA is useful for detecting metabolic impairment. ${ }^{32,33}$ Our observation is the same as individuals identified with high VF had higher prevalence of associated metabolic illnesses.

Dong-Hwa Lee in his study has shown that VFA estimated by multi frequency BIA was significantly correlated with VFA measured directly by CT. The BIA method tends to underestimate VFA with increase in BMI or age except for women aged $<50$ years or in those with a BMl $<25 \mathrm{~kg} / \mathrm{m} 2$. The application of a slightly modified formula using simply age, BMI, original VFA, and its interaction terms made the VFA values more accurate for the reference values obtained from CT scans.

In our study we estimated the visceral and total body fat in our enrolled patients using bioimpedance monitor and assessed their relation with BMI. Various studies have been conducted in this respect ${ }^{30-32,33,35,36,37}$ however no such study is reported from Pakistan.

A significant number of our patients in middle age category showed high values for $\mathrm{BMI}$ and visceral and total body fat as shown in other studies. ${ }^{5,36,37}$ Also these patients showed significant prevalence for associated diseases like diabetes and hypertension adding on to their cardiovascular risks. Thus we infer that obesity is a reason for concern in our region.

The females showed high BMI and total body fat percentage as compared to males same is reported in studies from other regions. ${ }^{6,7,35,36,37}$ The higher visceral fat values showed equal gender distribution but ratio of such males to total males in our group was higher. Thus indicating greater prevalence of visceral obesity among males. Visceral fat is a strong independent predictor of all-cause mortality in men. ${ }^{38}$

The application of WHO Asian-specific BMI trigger points for public health action to our study population led to increase in total number of obese individuals with simultaneous increase in number within high and very high categories of body and visceral fat. This observation adds weightage to our finding that number of high risk cases in our population is significant.

Bio-impedance based estimation showed a linear relationship between the three parameters as increase in BMI showed increase in body fat and visceral fat content as shown in Figure 1 and 2. 
However BIA and anthropometric methods have limited potential for accurately measuring visceral fat deposition in a clinical setting. It lacks specificity and accuracy because it is based on differences in resistance when an electrical current is conducted through fat and lean components of the body. Thus, prediction equations are used to determine fat-free mass. However, caution is required when interpreting these results as lean tissue measurements are influenced by hydration status, which is often a problem in clinical populations. If lean tissue measurements by BIA are imprecise, these errors will also confound fat measures.

Our limitation was small sample size therefore we can't generalize our findings to all Pakistanis. Larger group studies are required for accurate estimation.

In countries like ours where financial constraints are a major issue in dispensing health services plus the more accurate technologies involved in obesity assessment are not readily available the simple tool, based on bio-impedance,despite its limited potential can be utilized for classifying adipose tissue distribution for the initial diagnosis of abdominal obesity.

We recommend screening for visceral adiposity on larger scale using bio-impedance monitors especially in individuals with BMI above normal. Such patients should be counseled regarding their health risks and advised to have appropriate interventions to screen for associated illnesses and their management.

\section{CONCLUSION}

Prevalence of obesity and visceral adiposity in our population is a significant concern as it adds to cardio metabolic risk especially in middle aged population which also shows high prevalence of diabetes. Bio-impedance monitor though an indirect method and not very accurate can still be utilized to assess the body fat percentage and visceral fat content as an inexpensive tool in outdoor facility.

\section{ACKNOWLEDGEMENT}

We are thankful to Nestle Health Science Pakistan for providing the Bioimpedance monitor and Mr. Tipu Sultan and Mr. Khalid Mehmood Anjum for their help in data analysis.

\section{Authors contribution}

RK planed and designed the study, reviewed the literature, interpreted the results and wrote the initial and final draft.

IK collected and analyzed the data, interpreted the results, reviewed the literature and contributed in formatting the paper.

SL did literature search and contributed towards writing the introduction and discussion.

Copyright (C) 10 Feb, 2017.

\section{REFERENCES}

1. Emanuele Di Angelantonio, Shilpa N Bhupathiraju, David Wormser, Stephen Kaptoge , Pei Gao et al. Body-mass index and all-cause mortality: individual-participantdata meta-analysis of 239 prospective studies in four continents. Lancet 2016; 388: 776-86.

2. Kaess B.M., Pedley A., Massaro J.M., Murabito J., Hoffmann U., Fox C.S. The ratio of visceral to subcutaneous fat: A metric of body fat distribution is a unique correlate of cardio metabolic risk. Diabetologia 2012; 55: 2622-2630.

3. Britton KA, Massaro JM, Murabito JM, et al. Body fat distribution: Incident cardiovascular disease, cancer and all-cause mortality. J Am Coll Cardiol 2013; 62(10): 921-925.

4. Ritchie SA, Connell JM. The link between abdominal obesity, metabolic syndrome and cardiovascular disease. Nutr Metab Cardiovasc Dis 2007; 17:319-26.

5. Jackson AS, Stanforth PR, Gagnon J, Rankinen T, Leon AS, Rao DC, et al. The effect of sex, age and race on estimating percentage body fat from body mass index: the heritage family study. Int $\mathrm{J}$ Obes Relat Metab Disord 2002; 26(6): 789-796.

6. Kanaley JA, Sames C, Swisher L, Swick AG, PloutzSnyder LL, Steppan CM, et al. Abdominal fat distribution in pre- and postmenopausal women: the impact of physical activity, age, and menopausal status. Metabolism 2001; 50: 976-982.

7. Meeuwsen S, Horgan GW, Elia M. The relationship between BMI and percent body fat, measured by 
bioelectrical impedance, in a large adult sample is curvilinear and influenced by age and sex. Clin Nutr 2010; 29(5): 560-566.

8. Normal BMI Lowers Risk for Most Cancers, IARC Says August 25, 2016 By Amy Orciari.

9. Arnold M, Pandeya N, Byrnes G, Renehan A.G, Stevens G.A, Ezzat M. Global burden of cancer attributable to high body-mass index in 2012: A population-based study. Lancet Oncology 2015; 16(1): 36-46.

10. Gamage P, Katulanda P, Andraweera N, Thilakarathne S, et al. Relationship between Body mass index (BMI) and body fat percentage, estimated by bioelectrical impedance, in a group of Sri Lankan adults: a cross sectional study chathuranga ranasinghe. BMC Public Health 2013; 13: 797.

11. Vasudev S, Mohan A, Mohan D, Farooq S, Raj D, Mohan $V$. Validation of body fat measurement by skinfolds and two bioelectric impedance methods with DEXAthe Chennai Urban Rural Epidemiology Study. J Assoc Physicians India 2004; 52: 877-881.

12. Meeuwsen S, Horgan GW, Elia M. The relationship between BMI and percent body fat measured by bioelectrical impedance in a large adult sample is curvilinear and influenced by age and sex. Clin Nutr 2010; 29(5): 560-566.

13. Chen Y, Copeland WK, Vedanthan R, et al. Association between body mass index and cardiovascular disease mortality in East Asians and South Asians: pooled analysis of prospective data from the Asia Cohort Consortium. BMJ.2013; 347: 1-19.

14. Chiu M, Austin PC, Manuel DG, Shah BR, Tu JV. Deriving ethnic-specific BMI cutoff points for assessing diabetes risk. Diabetes Care 2011; 34: 1741-1748.

15. Connor Gorber S, Tremblay M, Moher D, Gorber B. A comparison of direct vs. self-report measures for assessing height, weight and body mass index: a systematic review. Obes Rev 2007; 8: 307-326.

16. Deurenberg P, Deurenberg-Yap M, Guricci S. Asians are different from Caucasians and from each other in their body mass index/body fat per cent relationship. Obes Rev 2002; 3:141-146.

17. Jane Jih, Mukherjea A, Eric VittinghoffTung T. Nguyen, et al. Using appropriate body mass index cut points for overweight and obesity among Asian. Americans pre Med 2014; 65: 1-6.

18. Flegal K.M, Kruszon-Moran D, Margaret D. Carroll, Fryar C.D., et al, Trends in obesity among adults in the United States, 2005 to 2014. JAMA. 2016; 315(21):
2284-2291.

19. Shah R.V, Murthy V.L, Abbasi S.A, Blankstein R, Kwong R.Y, Goldfine A.B, Jerosch-Herold M, Lima J.A, Ding $\mathrm{J}$, Allison M.A. Visceral adiposity and the risk of metabolic syndrome across body mass index: The MESA study. JACC Cardiovasc Imaging 2014; 7: $1221-$ 1235.

20. Hanley A.J, Wagenknecht L.E, Norris J.M, Bryer-Ash M, Chen Y.I, Anderson A.M, Bergman R, Haffner, S.M. Insulin resistance, beta cell dysfunction and visceral adiposity as predictors of incident diabetes: The insulin resistance atherosclerosis study (IRAS) family study. Diabetologia 2009; 52: 2079-2086.

21. Ghafoor MU, Mahmood-ur-Rehman, Irshad F. Screening tools for obesity; evaluation of waist hip ratio, waist circumference and BMI among hypertensive patients in a tertiary care hospital. Professional Med J 2016; 23(7): 844-857.

22. Matsuzawa $Y$, Funahashi T, Nakamura T. The concept of metabolic syndrome: Contribution of visceral fat accumulation and its molecular mechanism. J. Atheroscler. Thromb 2011; 18: 629-639.

23. Ritchie SA, Connell JM. The link between abdominal obesity, metabolic syndrome and cardiovascular disease. Nutr Metab Cardiovasc Dis 2007; 17: 319-26.

24. BerkerD, Koparal S, IsikS, Pasaoglu L.etal. Compatibility of different methods for the measurement of visceral fat in different body mass index strata. Diagn. Interv. Radiol 2010; 16: 99-105.

25. Shuster A, Patlas A, Inthus J.H., Mourtzakis M. The clinical importance of visceral adiposity: a critical review of methods for visceral adipose tissue analysis. Br. J .Radiol 2012; 85(1009): 1-10.

26. Kobayashi J, Tadokoro N, Watanabe M, Shinomiya $M$. A novel method of measuring intra-abdominal fat volume using helical computed tomography. Int $\mathrm{J}$ Obes Relat Metab Disord 2002; 26:398-402.

27. Kyle UG, Bosaeus I, De Lorenzo AD, Deurenberg P, Elia M, Manuel Gómez J, et al. Bioelectrical impedance analysis-part II: utilization in clinical practice. Clin Nutr 2004; 23:1430-53.

28. Nagai M, Komiya H, Mori $\mathrm{Y}$, Ohta T, Kasahara $\mathrm{Y}$, Ikeda $Y$. Development of a new method for estimating visceral fat area with multi-frequency bioelectrical impedance. Tohoku J Exp Med 2008; 214: 105-12.

29. Shoji K, Maeda K, Nakamura T, Funahashi T, Matsuzawa $Y$, Shimomura I, et al. Measurement of visceral fat by abdominal bioelectrical impedance analysis is 
beneficial in medical checkup. Obes Research Clin Pract 2008; 2:269-75.

30. Ryo M, Maeda K, Onda T, Katashima M, Okumiya A, Nishida $M$, et al. A new simple method for the measurement of visceral fat accumulation by bioelectrical impedance. Diabet. Care 2005; 28: 451453.

31. Nagai M, Komiya H, Mori Y, Ohta T, Kasahara Y, IkedaY. Estimating visceral fat area by multi frequency bioelectrical impedance. Diabet. Care 2010; 33: 10771079.

32. Unno M, Furusyo N, Mukae H, Koga T, Eiraku K, Hayashi $J$. The utility of visceral fat level by bioelectrical impedance analysis in the screening of metabolic syndrome-The results of the kyushu and okinawa population study (KOPS). J. Atheroscler. Thromb 2012; 19: 462-470.

33. Wang D, Li Y, Lee SG, Wang L, Fan J, Zhang G, et al. Ethnic differences in body composition and obesity related risk factors: study in Chinese and white males living in China. PLos One. 2011; 6(5): e19835.

34. Lee D.H, Park k.S, Soyeon Ahn, Eu Jeong Ku, et al. Comparison of Abdominal Visceral Adipose Tissue
Area Measured by Computed Tomography with that estimated by Bioelectrical Impedance Analysis Method in Korean Subjects Nutrients 2015; 7(12): 10513-10524.

35. Nair M, Ali M.K, Ajay V.S, Shivashankar R, et al. CARRS Surveillance study: design and methods to assess burdens from multiple perspectives. BMC Public Health 2012; 12: 701.

36. Gamage P, Katulanda P, Andraweera N, Thilakarathne S, et al. Relationship between Body mass index (BMI) and body fat percentage, estimated by bioelectrical impedance, in a group of Sri Lankan adults: a cross sectional study chathuranga ranasinghe. BMC Public Health 2013; 13: 797.

37. Meeuwsen S, Horgan GW, Elia M. The relationship between BMI and percent body fat, measured by bioelectrical impedance, in a large adult sample is curvilinear and influenced by age and sex. Clin Nutr 2010; 29(5): 560-566.

38. Kuk JL, Katzmarzyk PT, Nichaman MZ, Church TS, et al. Visceral fat is an independent predictor of allcause mortality in men. Obesity (Silver Spring) 2006; 14(2): 336-41.

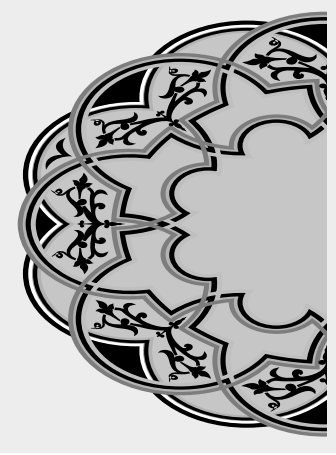

\section{"The measure of intelligence is the ability to change."}

Albert Einstein

\section{AUTHORSHIP AND CONTRIBUTION DECLARATION}

\begin{tabular}{|c|c|c|c|}
\hline Sr. \# & Author-s Full Name & Contribution to the paper & Author $=\mathbf{s}$ Signature \\
\hline 1 & Dr. Rizwana Kitchlew & $\begin{array}{l}\text { Conceive Idea, Study } \\
\text { design, Data collection, } \\
\text { Literature, Search } \\
\text { Manuscript writing }\end{array}$ & Hen \\
\hline 2 & $\begin{array}{l}\text { Dr. Aijaz Zeeshan Khan } \\
\text { Chachar }\end{array}$ & $\begin{array}{l}\text { Lieterature search, Data } \\
\text { collection and Analysis } \\
\text { interpretation, Review of } \\
\text { Manuscript }\end{array}$ & can. \\
\hline 3 & Sonia Latif & $\begin{array}{l}\text { Literature search assisted } \\
\text { in manuscript writing and } \\
\text { editing. }\end{array}$ & \\
\hline
\end{tabular}

